\title{
Security Management in the Air Transport: Example of an Interdisciplinary Investigation of Special Security Questions
}

\author{
Miroslav KELEMEN ${ }^{1}$, Stanislav SZABO ${ }^{2}$, Iveta VAJDOVÁ ${ }^{3}$
}

\author{
${ }^{1}$ Department of Flight Preparation, Faculty of Aeronautics, Technical University in Kosice, \\ Rampová 7, 04121 Kosice, Slovakia \\ ${ }^{2,3}$ Department of Air Transport Management, Faculty of Aeronautics, Technical University in \\ Kosice, Rampová 7, 04121 Kosice, Slovakia \\ E-mails: ${ }^{1}$ miroslav.kelemen@gmail.com; ${ }^{2}$ stanislav.szabo@tuke.sk; ${ }^{3}$ iveta.vajdova@tuke.sk
}

\begin{abstract}
Security management in the air transport is understood as an integral part of the activity and the decision-making process of the managers of the air operator and the security service, assigned to manage the security risks in the following dominant areas. The scientific cognition, investigation and complex education in the field of the situational security management within the range of a multidimensional relation "Human - Technique - Environment" in the transport that is perceived as a complex adaptive ergatic system within the context of available resources, it represents a creative activity in the field of security, quality and effectiveness of processes of the personnel education, performance and flight operation provision.
\end{abstract}

KEY WORDS: Security, air transport, investigation, security questions, airport security, flight safety

\section{Introduction}

The scientific cognition, expert education, education to professionalism and a challenging practical training of the personnel of the transport and specialized services providing and supporting its activity is rightfully in the center of our attention. The ambition of the experts is therefore to contribute to the development of the scientific investigation and education in the field of the security management in the transport (flight safety, security of persons and property, logistics and in the protection of the environment) [1].

\section{Method of Investigation}

The essential philosophy of the security management in the field of the air traffic service is a systematic approach to security risks and threats of the air transport. The most important component in the whole system of the security of flights is the management of the security of flights of the participants of the air traffic service. The security of flights is perceived as an internally integrated system of components (sub-systems) that respects its own identity (specifics, risks) and the existence of mutual relations and their connections with other areas of human activity, in line with the aim to eliminate the influence of the risk factors of a flight as well as of the service and to provide the maximum level of security of flights as a whole.

This article uses the historical and content professional and legal analysis to explore the issue [2].

\section{Investigation Results}

The term management of the security of flights can be defined as an active, predictive and preventive means within the range of a system of crisis management of a user of the aeronautical techniques (air operator) to eliminate the risks and solve exceptional events (situations) or crisis situations and states in the field of the security of flights.

An exceptional event (EE) in the air traffic service is understood as a dangerous flight or ground situation being a state in which life or health of the squad (passengers, other persons and property on the ground and in the air) or environment is threatened or in which the aeroplane loses the capability to fly or the security of the air traffic service is threatened or there is a risk that it might be. It occurs in case of a technical fault of an aeroplane, failure activity of the squad, ground personnel or device or by means of the influence of external conditions during the air traffic service.

An exceptional situation is understood as a situation with a threatening or real exceptional event. The exceptional event might turn into a crisis or catastrophic situation.

Depending on:

Corresponding author

E-mail address: ${ }^{1}$ miroslav.kelemen@gmail.com; 
- the conditions of the occurrence, process and consequences of a dangerous flight or ground situation,

- capabilities of flight and ground personnel or

- organs responsible for the security of the air traffic service to control these processes and perform non-standard processes, the following can occur:

a) an unflavored situation - a state that requires or shall require an increased duty of the flight or ground personnel to perform the flight and provide the operation,

b) a boundary situation - a state accompanied with a high psychical endurance of the flight and ground personnel or with a damage to the aeroplane (property, environment) or with the limitation of the air traffic service,

c) an emergency (crisis) situation - a state with such a level of threat of health of the squad (passengers, personnel, ...) that the squad is not able to solve it in any other way than by an attempt to save their life by means of a crash-landing in a terrain or by means of an emergency abandonment of the aeroplane, whereby it is not possible to prevent the destruction or damage to the aeroplane (property, local damage to the environment) or in case the security of the air traffic service is threatened,

d) catastrophic situation - a state in which it is highly probable that the lifesaving of the squad (passengers, personnel, ...) is not possible and it is not possible to prevent the destruction of the aeroplane (property, regional damage to the environment) or in case the security of the flights within the range of the air traffic service is threatened.

A successful solution to a dangerous flight situation is dependent on an individual level of the flight preparedness of the aeroplane squad, on the amount of time available to solve the situation, on the perplexity of the situation but mainly on the right evaluation of the situation, on an early decision making and performing effective measures and processes. As a result of a dangerous flight situation, a flight incident or a plane crash may occur.

The solution to a dangerous ground situation is dependent on the state that occurred in the time except for the time defined as a flight of an aeroplane, in relation to the preparation of the aeroplane for a flight, its operation, attendance, maintenance, repairs or waiting, on the control of persons (cargo) before the flight/after the flight the result of which is damage to health, death of a person or damage or destruction of the aeroplane (property, environment) or a threat as well as a violation of the security of the air traffic service by means of an influence of the ground factors.

Security management in the air transport is understood as an integral part of the activity and the decision-making process of the managers of the air operator and the security service, assigned to manage the security risks in the following dominant areas:

- The security of the air traffic service and;

- The security of airports.

In line with the model of the situational management of selected processes (in the area of the security of flights), we accept the following types of management (risk management):

- The management of tactical risks resulting from the usage of flight technique or security and defence measures in concrete crisis situations (terrorist attacks etc.) and

- The management of operational (organizational, regime, technical ...) risks that can influence the level of preparedness and the effectiveness of the applicability of the personnel.

In line with the model of the situational management of selected processes (in the area of the security of flights), we accept the following types of management (risk management):

- the management of tactical risks resulting from the usage of flight technique or security and defence measures in concrete crisis situations (terrorist attacks etc.) and

- the management of operational (organisational, regime, technical, ...) risks that can influence the level of preparedness and the effectiveness of the applicability of the personnel.

This implies that it is desirable that the goals and tasks of the security management for the protection of persons and property in a specified environment of the air transport are realised within the range of the mentioned risk management although it is not the only frame way.

The main goal of the security management in the air transport is the operation of the flight activity, provision, protection and defence of the air traffic service with an acceptable flight security level based on an elimination, reduction or management of potential risks.

The main tasks of the security management in the air transport are determined by the general goal mentioned and characterised depending on the particular level of management within the range of a complex system of the flight security management in the following way:

- to provide an effective prevention, primarily focusing on the reduction of plane crashed and incidents or a security (protection and defence) threat of the air traffic service by the fault of the human factor;

- to execute a consistent investigation of plane crashes, incidents and crisis situations in order to provide an acceptable flight operation security as the most valuable resource of prevention and a successful fulfilment of the assigned tasks;

- to perform the education and training of personnel in the field of the flight security, the priority being to prepare top managers, medium level managers and first-level managers (focusing on the commanders of plane squads and instructors of the flight training in the field of the flight operation and shift supervisors - guard commanders in the field of protection and defence of airports, security employees, ...);

- to organise and fulfil the tasks of the common training of the assigned components of the armed forces and particular components of the integrated rescue system;

- to perform the selection and management of human resources, to create legislative and material conditions for the 
fulfilment of tasks in the field of the flight security;

- to take measures and use appropriate tools to achieve the assigned partial goals in the field of the flight security;

- in case of crisis situations in the field of the flight security, to manage and coordinate the rescue or liquidation works within the range of the fulfilment of tasks of a crisis management system of a particular component;

- to fulfil the tasks of protection of persons and property in the air transport on the ground and aboard.

Within the range of the process management of the security of flight operations and airports, the organs of flight security management (security services) execute:

a) planned activities

- by means of a continuous identification and analysis of potential risks of the planned air traffic service (flight and ground), the importance being attached to the area of human resources, material-technical provision, security and operation conditions of the air traffic service;

- by means of making preventive decisions and by means of realisation of preventive measures in terms of planning, organisation, execution, provision and protection of the air traffic service in the days of the flight activity, in line with the approved planning documents (schedules of the air traffic service, flight plans);

- by means of making preventive decisions and realisation of flight security regulations in case of an individual fulfilment of flight tasks within the range of a selected effort of the aeronautics in behalf of other branches or in case of the air transport provision;

- by means of protection and ensuring the airport security based on a combination of three basic types of protection: - physical protection,

- by means of using mechanical barrier means and technical guard means (the importance being attached to the radar and monitoring technique, the usage of pilotless means etc.)

- by means of regime protection;

- by means of a continuous control activity and by means of an evaluation of the whole operation process, by means of securing and protecting the air traffic service, in the field of the flight security;

b) operative activity

- by means of making decisions and realisation of regulations to provide the flight security, in case of the fulfilment of flight tasks;

- by means of making decisions and realisation of preventive measures based on performed security risk analyses, by means of control activities or violation of the assigned principles and regime in case of securing or protecting the air traffic service.

Within the range of solving a crisis situation, the flight security (security service) management organs usually execute:

a) planned activities

- within the range of management and control of an assigned group of persons to solve the crisis situations;

- within the range of coordination and collaboration with other crisis management system organs;

- within the range of a permanent physical and technical control of the inputs, outputs and the movement of persons (own and strange personnel, passengers, ...), mobile and static means in the area of the airport and near the airport, material control (cargo, post, ...);

- the importance being attached to a continuous identification and analysis of the security situation and risks of the air traffic service in the air and on the ground;

- the importance being attached to the evaluation of available radar information about the air situation (primarily from own review and landing radars of the airport);

- in line with the regulations for the air searching and ground searching rescue service;

- in line with the plan of the assigned forces and means of the air operator and the security service for crisis situations;

b) operative activity

- by means of making decisions regarding the supplementing of forces and means for the crisis situations according to the security situation state from the airport environment and a particular finishing controlled area of the air space (the airport space);

- the importance being attached to the analysis of the information from technical means of protection, from air guardians, strong points of the protection and defence of an airport, from available radar means of air units and pilotless devices to monitor the air and ground situation in the threatened interest areas;

- within the range of a co-operation with other parts of the crisis management system, mainly other parts of the integrated rescue system of the Slovak Republic.

The security management for the protection of persons and property in the air transport respects the specific environment and conditions of the air traffic service as well as of the airport security. In a significant way, it participates in the increase of the professional preparedness of the flight and ground personnel for the handling of difficult security and crisis situations during the flight, at the airport and outside the airport.

The task of the research in the field of the flight security is predominantly the scientific analysis of preventivesecurity information (from the field of the flight security, flight preparation, investigation, preventive activities, provision and protection of the air traffic service, aeronautic technique operation), investigation of the security risks and threats as well as searching for optimal solutions in order to prevent exceptional events and crisis situations, today, primarily within the range of the fight against terrorism.

We are convinced that the security management in transport is primarily a realisation knowledge and situational 
realisation expressed by means of acquired and trained competences of employees (or, more precisely, of the operators, squad) of a means of transport, aeroplane, flight operation commander, maintenance worker, security manager etc., in a challenging process of their professional education and training for the performance of expert functions.

The management of the development of competences of transport experts is distinguished by the limitedness of their competences in the security problem solving process, by means of narrowing and modifying the known ideas considering situational gaps in which the mistakes may be generated predominantly by the operators of the means of transport during the transport, by the flight operation commander, boatman, engine-driver or maintenance technician.

The security management in the sectors of national critical infrastructure is the important part of the protection of state interests [3].

\section{Conclusions}

The security disciplines based on general bases of the scientific work methodology and the application of the methodology of practical disciplines in a specific environment of the protection and defence of lives and health of citizens, protection of their properties and protected interests of a society or a communion of countries can also contribute to the fight against antisocial phenomena by means of the application in the field of a complex security dimensions research. We see the position of the antisocial phenomena investigation within the range of the security disciplines primarily within the context of the investigation of the protection of human rights and minorities - the protection of persons and properties, or, more precisely, civil protection, fight against intolerance, discrimination and extremism and within the range of the investigation of criminality prevention and the work with the youth.

\section{Acknowledgements}

This work was conducted within the framework of the Establish a national risk assessment and management of the security risks strategy. The authors are thankful for the cooperation provided by the Ministry of Foreign Affairs of the Slovak Republic.

\section{References}

1. Kelemen, M. Information problems of the air accidents' investigation and the prevention of the Air Force accidents: Theory and practise of forensic investigation of the crime of general threats. Boguchwala: Publishing house AMELIA Aneta Siewiorek, 2017. 171 p.

2. Kelemen, M. Vybrané problémy ochrany osôb, majetku a zaistenia chránených záujmov v sektoroch bezpečnosti. Bratislava: VEDA vydavatel'stvo SAV, 2014, 371 p.

3. Kelemen, M. Problems of protected interests in the security sectors: Professional and criminal law aspects of the protection of interests. Banská Bystrica: Belianum. Publishing house of Matej Bel University, 2017. 112 p.

4. Szabo, S., Němec, V., Soušek, R. Management bezpečnosti letiště. 1. vyd. Brno: Akademické nakladatelství CERM, 2015. 165 s. ISBN 978-80-7204-933-2.

5. Socha, V., Socha, L., Szabo, S., Němec, V. Air accidents, their investigation and prevention. In: eXclusive e-JOURNAL. 2014, no. 4, ISSN 1339-4509.

6. Insider threat in civil aviation. Available at: https://www.iata.org/policy/Documents/insider-threats-position. 